\title{
Reduction of Renal Ischemia-Reperfusion-Induced Liver Side Effects in Rats through Antioxidative Properties of Narigenin
}

\author{
Shiva Roshankhah 1(D), Amir Abdolmaleki ${ }^{1}$ iD, Mohammad Reza Salahshoor ${ }^{(D)}$ \\ 1. Dept. of Anatomical Sciences, School of Medicine, Kermanshah University of Medical Sciences, Kermanshah, Iran
}

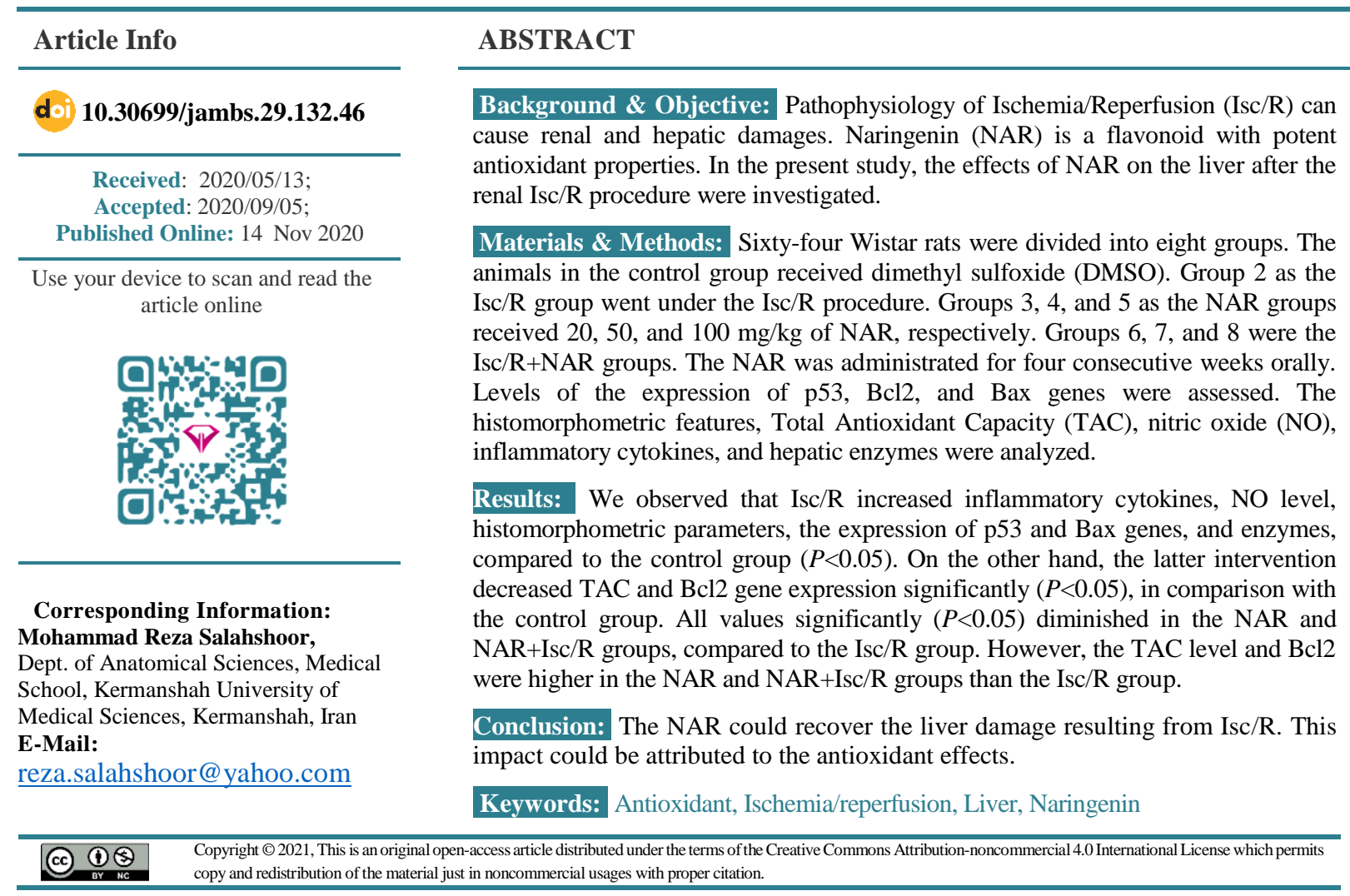

\section{Introduction}

Induction of Isc/R in kidney and renal injury can potentially affect the liver (1). Reduced blood supply to an organ or the presence of complete ischemia can easily lead to oxidative stress in tissue similar to the Isc/R process (2). Oxidation occurs through two main pathways, including respiratory burst in WBCs and insufficient oxygen supply to the tissue $(3,4)$.

Today, it has been proven that many herbal remedies exert therapeutic effects against pathologic conditions through the antioxidant potential (5). Therefore, the flavonoids in plants are known as the main source of antioxidants in Chinese herbal medicine (6). Monoflavonoids and polyflavonoids are two major types of flavonoids (7). The main subsets of natural bioflavonoids are 4',8'-linkage bioflavonoids and 6'O,3",-linkage bioflavonoids (8). Naringenin (NAR) is a natural monoflavone found in grapefruits and tomatoes with proven medicinal properties (9).

Andrade et al. compared the biomedical contents of various species of propolis and found that phenolic compounds have higher antioxidant capacity than flavonoids (10). Moreover, the biochemical constituents and antioxidant properties of purple and yellow Chrysanthemum were analyzed in another study (11) concluding that the yellow type of Chrysanthemum contains high amounts of NAR with fewer antioxidant properties than the purple types (rich in anthocyanin) (12).

Gouveia et al. found higher antioxidant potential for the phenolic part of Chrysanthemum, in comparison with flavonoids (13). Meanwhile, antioxidant features related to flavonoids, such as NAR have been approved. Lou et al. in an experimental study on Kumquat extracts reported high levels of antioxidants associated with phenolic and flavonoid contents. They confirmed some obvious features of NAR in Kumquat extracts, such as removing free radicals and apigenin sorption (14).

Peter et al. compared NAR and the related dimer (i.e., isoginkgetin) in terms of extra Reactive Oxygen Species (ROS). They revealed that isoginkgetin was more effective than NAR in ROS scavenging. However, NAR is changed into dimers in antioxidant reactions (15). Furthermore, in experimental studies, 
the therapeutic influences of NAR on liver diseases were approved (16). It has been noted that NAR has antioxidant and anti-inflammatory therapeutic impacts on Liver diseases.

Inhibiting the production of interleukin-1 beta (IL$1 \beta$ ) and tumor necrosis factor-alpha (TNF- $\alpha$ ) along with enhancing the antioxidant capacity of RAW 134.9 macrophages are known as the major impacts of NAR in the field of antioxidant and anti-inflammation activities (17-19). There are few analytic studies concerning the potential activity of NAR in liver failure following renal Isc/R and no precise outcomes have been noted about the effects of this substance on the expression of apoptotic genes, inflammatory cytokines, and NO levels. Consequently, we investigated the therapeutic effects of NAR on liver physiopathology and inflammation following the induction of renal Isc/R in Wistar rats.

\section{Materials and Methods}

\section{Animals}

Sixty-four male Wistar rats aged 12-14 weeks and weighing $250 \pm 30 \mathrm{~g}$ were prepared from Pasteur Institute, Tehran, Iran. Conditions for keeping laboratory animals based on the ethics of animal care were the temperature of $22 \pm 2^{\circ} \mathrm{C}$ and photo-cycle of 12 light/12 dark. All treatments on laboratory animals were conducted according to the Ethics Committee of Kermanshah University of Medical Sciences (No.1396.348) (20).

\section{Experiment Design and Surgery}

A total of 64 animals were divided into eight groups as follow: 1) control group (0.1\% DMSO, surgical procedures with no artery occlusion), 2) Isc/R group (DMSO injection followed by bilateral renal 30-min ischemia and 24-h reperfusion), 3-5) NAR groups (abdominal walls were sutured one hour following laparotomy, gavage with $0.1 \%$ DMSO+25, 50, and 100 $\mathrm{mg} / \mathrm{kg}$ of NAR, 6-8) NAR+Isc/R groups (bilateral renal 30 -min ischemia followed by $24-\mathrm{h}$ reperfusion, gavage with $\mathrm{DMSO}+25,50$, and $100 \mathrm{mg} / \mathrm{kg}$ of NAR a day after surgery).

Anesthesia was induced by the intraperitoneal administration of xylazine/ketamine $(10 / 70 \mathrm{mg} / \mathrm{kg})$. The animals were treated for 28 days and were killed by cervical dislocation. Blood samples were attained through needle insertion into the left ventricle. Samples were incubated for $20 \mathrm{~min}$ at room temperature and were centrifuged at $3000 \mathrm{rpm}$ for $10 \mathrm{~min}$. The sera were kept at $-20^{\circ} \mathrm{C}$ for enzyme measurements (9). In addition, the liver tissues were dissected after laparotomy for future analysis.

\section{Histomorphometric Assessments}

The right lobe of the liver was fixed in $10 \%$ buffered formaldehyde. Following the application of the routine histological process, the paraffin blocks were cut as sections of $5 \mu \mathrm{m}$ (Leica RM2125, Germany) and were stained by H\&E. The captures were completed using a microscope (Olympus CZ-41F 56S02) and Olysia Biosoftware (Olympus Optical, Japan) was used for image morphometrical analysis. Subsequently, quantitative histological indices were measured in 50 hepatocytes of each subject, including the diameter of the central hepatic vein, the diameter of hepatocytes, as well as the longest and shortest axis of the cells. A similar technique was performed for the central vein measurements (3).

\section{Liver TAC Level}

TAC levels were analyzed by a commercial kit (Cat No: TAC-96A, ZellBioGmbH, Germany) utilizing the colorimetry method. Ascorbic acid was considered a standard. In this kit, sensitivity, diagnostic range, and final absorbance were $0.1 \mathrm{mM}, \mathrm{mM} 0.125-2$, and 540 $\mathrm{nm}$, respectively (21).

\section{NO Level}

In this study, the Griess reagent was applied in an acidic medium. First, $10 \mathrm{mg}$ of zinc sulfate was added to $200 \mu \mathrm{L}$ of the sample. Next, a mixture of $100 \mu \mathrm{L}$ of sulfonamide, $25 \mu \mathrm{L}$ of NEDD, and $200 \mu \mathrm{L}$ of chloride vanadium was added to the previous combination. Following incubation in a dark environment $\left(25^{\circ} \mathrm{C}\right)$, the optical density was measured at the wavelength of $540 \mathrm{~nm}(21)$.

\section{Inflammatory Cytokines}

Radio-immunoprecipitation Assay Lysis Buffer was used for tissue $(100 \mathrm{mg}$ ) lysis (Abcam, Cambridge, $\mathrm{UK}$ ) and centrifugation was performed at $30000 \mathrm{~g}$ and $4^{\circ} \mathrm{C}$ for $15 \mathrm{~min}$. Inflammatory biomarkers in the liver homogenate, namely TNF $\alpha$, IL $1 \beta$, and TLR 4 were analyzed by the enzyme-linked immunosorbent assay ELISA kits (Abcam, Cambridge, UK and MyBioSource, California, USA) and absorbance measurement (16).

\section{Plasma Level of Liver Enzymes}

The measured liver enzymes were alanine transaminase (ALT), Aspartate Transaminase (AST), total bilirubin, and albumin as the indicators of liver activity. The latter factors were measured by spectrophotometry kits (Pars Azmun, Tehran, Iran) according to the instructions of the manufacturer (21).

Real-time Polymerase Chain Reaction
Desired genes entailed p53 (F: $\begin{array}{r}50- \\ \text { AAGCTCATTTCCTGGTATG-30/ }\end{array}$ R:50-
CTGCCACAAGAACTAGAGA-30), Bcl2 (F: 50TGG GATGCCTTTGTGGAACT-30/R: 50GAGAC AGCCAGGAGAAATCA-30), and Bax (F: 50-ATGGCGAAATGGAGATGAATA-30/ R:50GCATGGGCATCCTTTAACTC-30). The expression levels of these genes were analyzed utilizing real-time polymerase chain reaction (PCR).

The RNeasy mini kit (Qiagen Co.,Valencia, CA, USA) and RevertAid ${ }^{\mathrm{TM}}$ First Strand cDNA Synthesis Kit (Fermentas, Vilnius, Lithuania) were applied for total RNA extraction and cDNA synthesis of liver tissue. The levels of gene expression were measured by glyceraldehyde-3-phosphate dehydrogenase primer 


\section{(F: 50- AAGCTCATTTCCTGGTATG-30/ \\ R: 50- CTGCCACAAGAACTAGAGA-30)} as endogenous control and SYBR Green (22).

\section{Statistical Analysis}

The one-way ANOVA and Tukey post-hoc tests were used for data analysis by the SPSS software version 16 (SPSS Inc, Chicago, Ill., USA). The final results are shown as Mean \pm SEM. P-value $<0.05$ was considered statistically significant.

\section{Results}

\section{Quantitative Histological Parameters}

In hepatocytes and central hepatic veins of the experiment groups, the mean diameter was significantly different between the control and Isc/R groups $(P<0.05)$. On the other hand, none of these values had a significant difference between the NAR and control groups $(P>0.05)$. In the NAR and NAR+Isc/R groups, these two morphological features reduced significantly, compared to the Isc/ $\mathrm{R}$ group $(P<0.05)$ (Figures 1 and 2$)$.
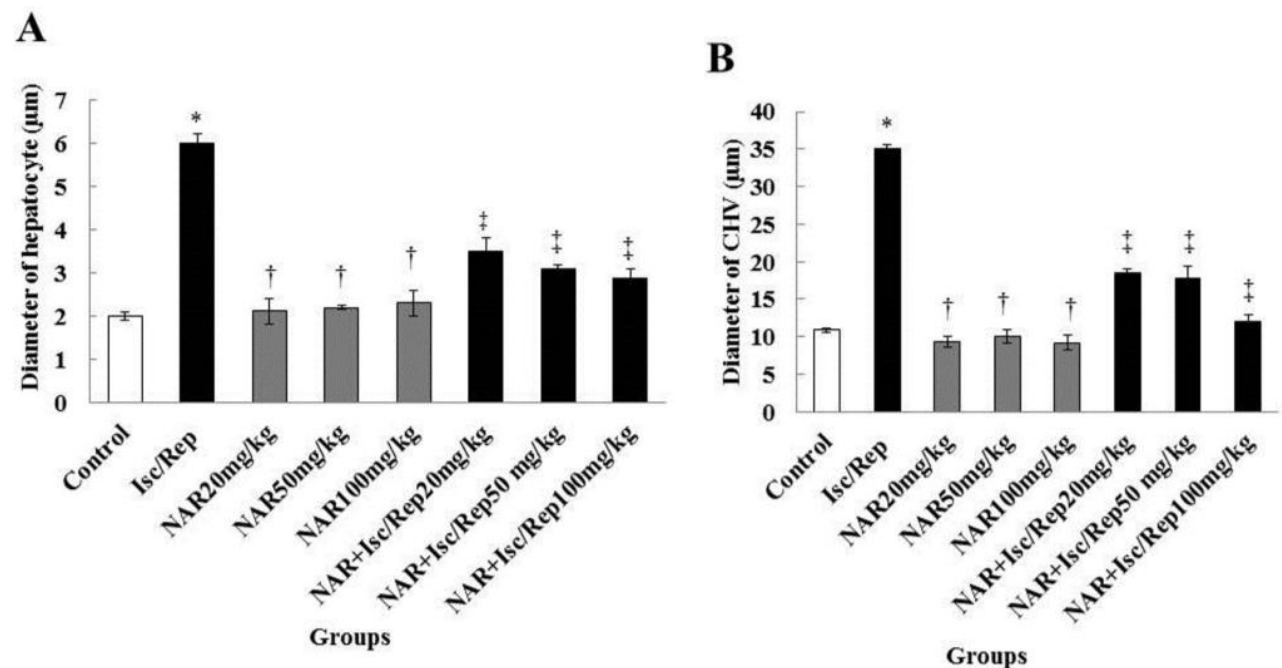

Figure 1. Effect of Isc/R and NAR administration on the diameter of hepatocytes (A), and central hepatic vein (B). *Significant differences between the diameters of hepatocytes and central hepatic vein with the control group $(P<0.05)$. $\uparrow$ Significant differences, compared to the Isc/R group $(P<\mathbf{0 . 0 5})$. $\ddagger$ Significant differences, compared to the Isc/ $\mathbf{R}$ group $(P<0.05)$. CHV: central hepatic vein, NAR: naringenin, Isc/Rep: ischemia-reperfusion

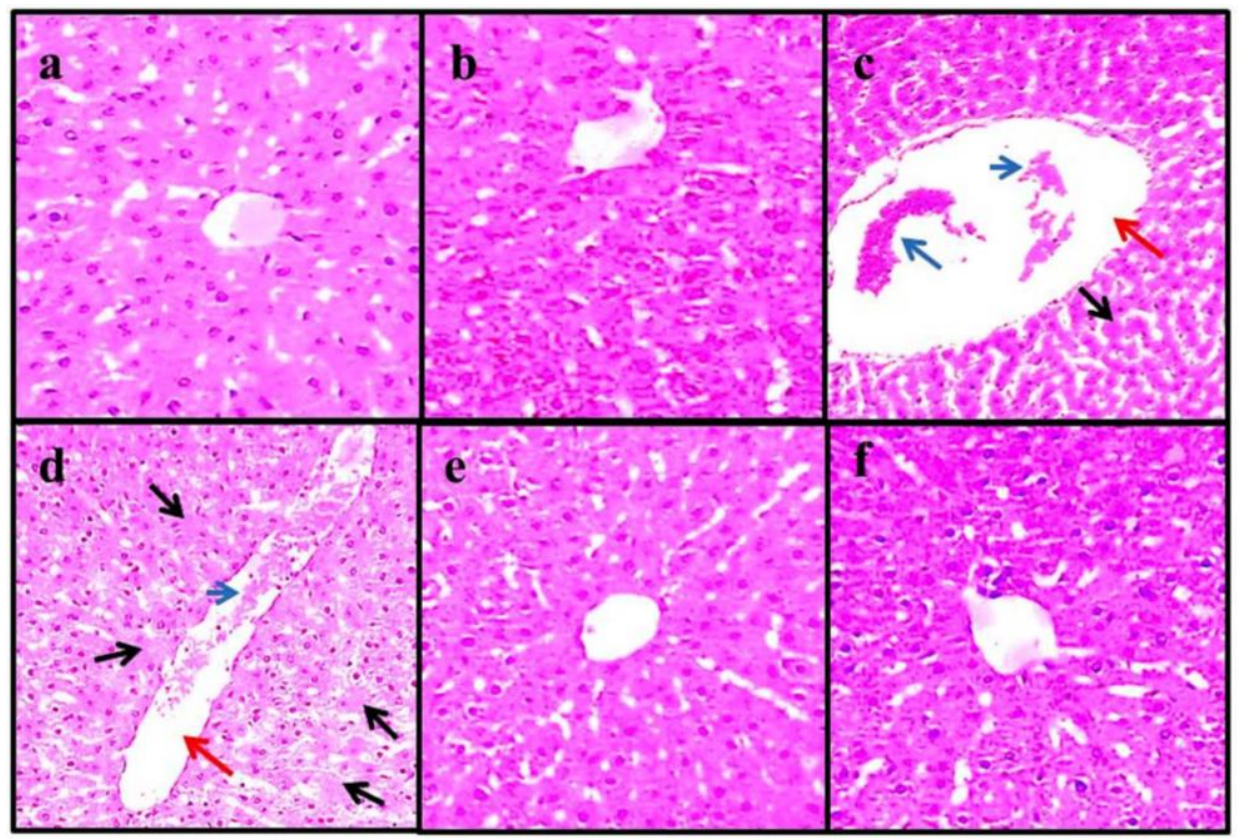

Figure 2. Histological images of the experiment groups $(4 \mu \mathrm{m}, \mathrm{H} \& \mathrm{E}, \times 100)$. Groups of control (a), NAR (100 mg/kg) (b), NAR (50 mg/kg)+Isc/R group (e), and NAR (100 mg/kg)+Isc/R group (f). Cell destruction with no nuclei (black arrows), dilatation in the central hepatic vein (red arrows), and hyperemia (blue arrow) in the Isc/R group (c, d). NAR: naringenin, Isc/Rep: ischemia-reperfusion 


\section{STAC Levels}

The TAC value of the Isc/R group was observed to be significantly lower than the control group $(P<0.05)$. Furthermore, the TAC level was found to be higher in the NAR and NAR+Isc/R groups than in the Isc/R group $(P<0.05)$. In contrast, no significant effects were found on the TAC level in neither of the NAR groups, compared to the control group $(P>0.05)$ (Figure 3$)$.

\section{NO levels}

The level of TAC increased significantly $(P<0.05)$ in the Isc/R group with no significant changes noted in neither of the NAR groups $(P>0.05)$. Moreover, NO levels were shown to be significantly lower in all NAR and NAR+Isc/R groups, compared to the Isc/R group $(P<0.05)$ (Figure 3 ).

\section{Gene Expression Levels}

Up-regulated modifications of apoptotic p53 and Bax genes and down-regulated variations of the $B c l 2$ gene were identified as significant $(P<0.05)$ in the $\mathrm{Isc} / \mathrm{R}$ group. Significant down-regulation of p53 and Bax genes and up-regulation of the $B c l 2$ apoptotic gene were revealed in the NAR and NAR+Isc/R groups, while the alterations were not significant in the Isc/R group (Figure 3).

\section{Inflammatory Cytokines}

Levels of inflammatory cytokines were significantly higher in the Isc/R group, in comparison with the control group $(P<0.05)$. The NAR was able to augment the levels of inflammatory cytokines significantly $(P<0.05)$ in the NAR and NAR+Isc/R groups, compared to the Isc/ $\mathrm{R}$ group. The changes in the levels of inflammatory cytokines were not significant in the NAR group $(P>0.05)$ (Table 1).
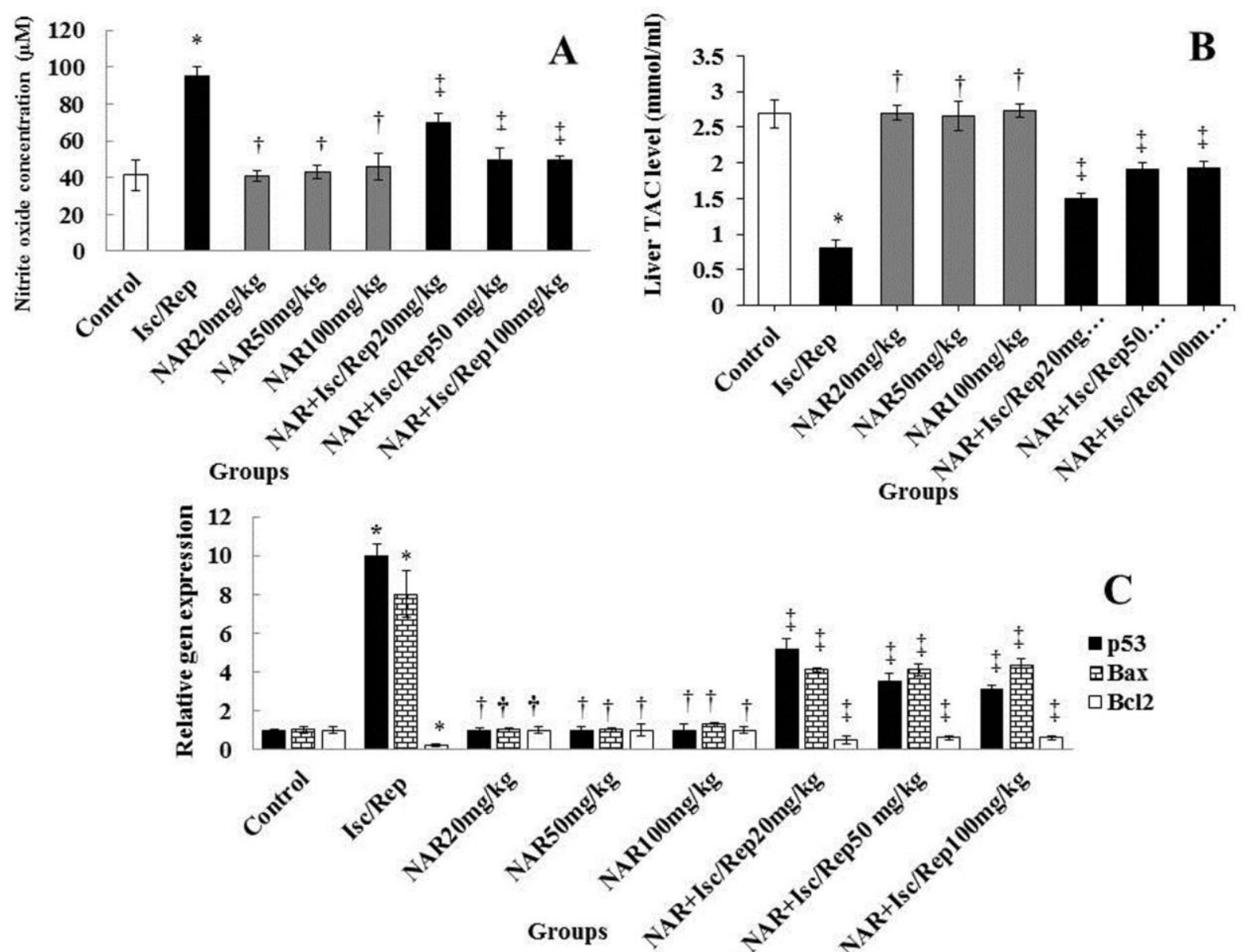

Figure 3. Isc/R and NAR affect the levels of NO (A) and TAC (B), and the expression of genes (C). *Significant differences, compared to control $(P<0.05)$. $\dagger$ Significant differences, in comparison with Isc/ $\mathbf{R}(P<0.05) . \dagger$ Significant differences with Isc/R $(P<0.05)$. NAR: Naringenin, Isc/Rep: Ischemia-reperfusion, NO: nitric oxide 
Table 1. Differences of inflammatory bio-markers among treatment groups

\begin{tabular}{ccccccccc} 
Enzyymes(ng/ml) & Control & Isc/R & \multicolumn{2}{c}{ NAR } & \multicolumn{3}{c}{ NAR + Isc/R } \\
& & & $10 \mathrm{mg} / \mathrm{kg}$ & $25 \mathrm{mg} / \mathrm{kg}$ & $50 \mathrm{mg} / \mathrm{kg}$ & $10 \mathrm{mg} / \mathrm{kg}$ & $25 \mathrm{mg} / \mathrm{kg}$ & $50 \mathrm{mg} / \mathrm{kg}$ \\
\hline $\mathrm{TNF} \alpha$ & $11.45 \pm 1.71$ & $51.25 \pm 5.03^{*}$ & $10.07 \pm 1.36 \dagger$ & $9.22 \pm 1.72 \dagger$ & $10.01 \pm 2.64 \dagger$ & $23.4 \pm 2.77 \ddagger$ & $22.1 \pm 2.54 \ddagger$ & $20.3 \pm 1.23 \ddagger$ \\
\hline $\mathrm{IL} 1 \beta$ & $6.54 \pm 0.20$ & $25.53 \pm 1.31^{*}$ & $8.08 \pm 0.54 \dagger$ & $7.22 \pm 0.99 \dagger$ & $7.11 \pm 1.01 \dagger$ & $14.7 \pm 1.42 \ddagger$ & $13.3 \pm 1.91 \ddagger$ & $11.7 \pm 1.97 \ddagger$ \\
\hline TLR4 & $0.27 \pm 0.01$ & $0.81 \pm 0.08^{*}$ & $0.26 \pm 0.03 \dagger$ & $0.27 \pm 0.04 \dagger$ & $0.26 \pm 0.01 \dagger$ & $0.45 \pm 0.05 \ddagger$ & $0.41 \pm 0.01 \ddagger$ & $0.40 \pm 0.03 \ddagger$ \\
\hline
\end{tabular}

Mean \pm standard deviation was used for data presentation. TNF $\alpha$ : Tumor necrosis factor-alpha, IL1 $\beta$ : Interleukin 1 beta, TLR4: Toll-like receptor 4, NAR: Narigenin, Isc/R: Ischemia-reperfusion. * P-value $<0.05$ than control. $\dagger \mathrm{P}$-value $<0.05$ compared to Isc/R group. $\$$ P-value $<0.05$ compared to the Isc/R group.

\section{Liver Functional Enzymes}

In the Isc/R group, significant elevation was reported in ALT, AST, and ALP levels $(P<0.05)$. Furthermore, the mean concentration of these enzymes did not change significantly in either NAR groups $(P>0.05)$. The mentioned enzymes were significantly lower in the NAR and NAR+Isc/R groups of all doses than in the Isc/R group $(P<0.05)$ (Table 2$)$.

Table 2. Differences of liver enzymes among treatment groups

\begin{tabular}{ccccccccc} 
Enzymmes(ng/ml) & Control & Isc/R & \multicolumn{2}{c}{ NAR } & & \multicolumn{2}{c}{ NAR + Isc/R } \\
& & & $10 \mathrm{mg} / \mathrm{kg}$ & $25 \mathrm{mg} / \mathrm{kg}$ & $50 \mathrm{mg} / \mathrm{kg}$ & $10 \mathrm{mg} / \mathrm{kg}$ & $25 \mathrm{mg} / \mathrm{kg}$ & $50 \mathrm{mg} / \mathrm{kg}$ \\
\hline AST & $43.14 \pm 2.06$ & $132.22 \pm 5.78^{*}$ & $42.09 \pm 2.31 \dagger$ & $41.1 \pm 2.01 \dagger$ & $41.5 \pm 3.23 \dagger$ & $62.7 \pm 2.45 \ddagger$ & $60.2 \pm 5.71 \ddagger$ & $60.3 \pm 2.11 \ddagger$ \\
\hline ALT & $32.43 \pm 1.32$ & $82.73 \pm 5.78^{*}$ & $32.91 \pm 3.36 \dagger$ & $31.7 \pm 1.41 \dagger$ & $31 \pm 2.07 \dagger$ & $58.4 \pm 3.41 \ddagger$ & $58.8 \pm 3.13 \ddagger$ & $55.1 \pm 2.13 \ddagger$ \\
\hline ALP & $2.81 \pm 0.01$ & $7.98 \pm 0.10^{*}$ & $2.71 \pm 0.01 \dagger$ & $2.22 \pm 0.08 \dagger$ & $2.31 \pm 2.11 \dagger$ & $4.74 \pm 0.72 \ddagger$ & $4.44 \pm 0.34 \ddagger$ & $3.36 \pm 4.11 \ddagger$ \\
\hline
\end{tabular}

Data presentation were as mean \pm standard deviation. ALP: Alkaline phosphatase, ALT: Alanine aminotransferase, AST: Aspartate aminotransferase, NAR: Narigenin, Isc/R: Ischemia-reperfusion. * P-value $<0.05$ compared to the control group. $\dagger \mathrm{P}$-value $<0.05$ compared to Isc/R group. $\ddagger \mathrm{P}$-value $<0.05$ compared to the Isc/R group.

\section{Discussion}

According to the results of this investigation, 60min renal Isc followed by 5-day Rep resulted in histological liver damages, p53 and Bax genes upregulation, the disruption of balance in the hepatic enzyme, the induction of imbalance in the liver oxidative-antioxidant system, and significantly elevated inflammatory cytokines. Moreover, inflammation following Isc/Rep induction can lead to hepatic NO generation. The NAR can recover the mentioned damages in the liver by the antioxidant impact.

The findings of the present study showed significant alterations in the histopathology of liver, liver enzymes, and antioxidant balance. In addition, we concluded that NAR is effective in the restoration of these destructive changes. Wang et al. found an increase in the level of serum hepatic enzymes following 1-h Isc/4-h R (23). Furthermore, it was approved by Seifi et al. in a 45-minute treatment (24).

According to the literature, the liver responds to Isc/R by changing the enzymatic content. Therefore, it could be concluded that alterations in the serum level of hepatic enzymes are considered as the main reaction to the renal Isc/R procedure. Reduced Isc and elevated Rep time might diminish hepatic injury (4, 5).

In pulmonary tuberculosis, increased indirect level of alkaline phosphatase (ALP) was detected, while a cholestatic pattern could be diagnosed based on levels of ALP, AST and ALT. Therefore, it can be stated that Isc/ $R$ is influenced by the cholestasis pattern of liver damage and liver function. The ability of the normal liver to produce albumin could be considered in this regard (25). The albumin available in blood serum may decline as a result of pathologic conditions affecting the liver following Isc/R. Consequently, albumin could be regarded as a crucial biochemical marker.

Damaged tissue in Isc/ $R$ generates excessive amounts of ROS leading to oxidative stress. These excessive ROS are directed to the liver tissue by the bloodstream and cause damage (3). In animals under Isc/R, increased diameters of hepatocytes and central veins were detected, which was approved by other investigations following nicotine administration (26). 
Furthermore, in the current study, we demonstrated that NO could lead to the dilatation of the central hepatic vein. The NO plays role in the exacerbation of liver histopathology, such as the increased diameter of the central vein (21). Along with the elevated level of NO in liver tissue, other destructive agents are produced following Isc/R, which can also lead to the vasodilation of the central hepatic vein (27). While NAR can change the pathologic features of the liver to the normal form (28). This confirms the association of histological features with liver function following Isc/R.

The histopathological changes associated with the augmented level of NO could trigger oxidative stress process and acute changes, including steatosis and the atrophy of hepatocytes. It is approved that the previously mentioned histological alterations would disappear gradually with no changes in the volume of hepatocytes and the diameter of central veins (29). Consequently, long-time exposure to NO is critical for toxin elimination leading to the growth of hepatocytes.

In the current investigation, the data revealed significantly increased TLR4 expression in Isc/R rats. Furthermore, NO level and inflammatory biomarkers are correlated in lipopolysaccharide-induced acute lung injuries (30). In the Sertoli cells of rats, activated TLR-5 up-regulates the expression of inflammatory cytokines resulting in diminished testosterone and spermatogenesis (16).

The NAR administration could decrease these proinflammatory cytokines with lower influence on TNF- $\alpha$ and higher impact on IL-10 and IL-6 (31). Generally, TLRs, inflammatory cytokines, and NO levels are positively correlated (27). We found significant positive correlations between $\mathrm{TNF} \alpha$, IL $1 \beta$, and NO. This result is consistent with the findings of Pari et al., in which a relationship was reported between TLR-4 and IL-5 in cardiomyocyte Hypoxia/Reoxygenation damage (19).

The stimulation of inflammatory cytokines secretion and the presence of TLR could be considered as a general linking cascade, the upregulation of which is not related to the Isc/R process. In the present study, NAR decreased the hepatic damages caused by Isc/R. The NAR may create protective effects against the pathologic conditions of antioxidants accumulation in the liver. Roshankhah et al. reported that the Petroselinum crispum controlled the damage caused by Isc/R (20). We observed that NAR down-regulated the expression of Bax and p53 apoptotic genes, while up-regulated the $\mathrm{Bcl} 2$ gene. The p53 moderates the activity of apoptotic elements, such as Caspase and Bax (32).

It is suggested that Isc/Rep had up-regulatory effects on the apoptotic genes (33). Furthermore, NAR is translocated within the intra-nuclear space to induce the down-regulation of the related genes (34).
Bayir et al. reported that the apoptotic genes are expressed significantly in the pheochromocytoma of the adrenal medulla in rats after Isc/Rep (29). In the current study, NAR reduced the expression of Bax and p53 and improved the expression of the Bcl2 gene to prevent cell death.

\section{Conclusion}

The results of this study indicated that 60-min renal Isc followed by 5-day Rep caused liver damage, the upregulation of p53 and Bax genes, disturbed hepatic enzymes, and the induction of imbalance in the liver oxidant-antioxidant system. The administration of NAR reduced the damages to the liver tissue. The induced inflammation following Isc/Rep might result in NO generation in the liver. The increased level of $\mathrm{NO}$ in chronic hepatic inflammation could be attributed to the recovery of inflammation. In addition, NAR is recommended to be influential in the removal of these histopathologic landmarks.

\section{Acknowledgments}

We are grateful to the Research Council of Kermanshah University of Medical Sciences for their financial support.

\section{Ethical considerations}

Ethical issues (Including plagiarism, informed consent, misconduct, data fabrication and/or falsification, double publication and/or submission, redundancy, etc.) have been completely observed by the authors.

\section{Funding and support}

This research resulted from an independent research without receiving any financial support.

\section{Conflict of Interest}

Authors declared no conflict of interest.

\section{References}

1. Fang T, Koo TY, Lee JG, et al. Anti-CD45RB antibody therapy attenuates renal ischemiareperfusion injury by inducing regulatory B cells. J Am Soc Nephrol. 2019; 30(10): 1870-85. [DOI:10.1681/ASN.2018101067]

2. Roshankhah S, Jalili C, Salahshoor MR. Protective effects of Petroselinum crispum on ischemia/reperfusion-induced acute kidney injury in rats. Physiol Pharmacol. 2019; 23(2): 129-39.

3. Salahshoor MR JC, Roshankhah S. Can royal jelly protect against renal ischemia/reperfusion injury in rats? Chin J Physiol. 2019; 62: 131-7. [DOI:10.4103/CJP.CJP 36 19] 
4. Behaghel V, Tamareille S, Rabant M. Remote ischemic conditioning in a model of severe renal ischemia-reperfusion injury. Shock. 2019; 51(6): 795-9. [DOI:10.1097/SHK.0000000000001187]

5. Ahmadvand H, Babaeenezhad E, Nasri M, Jafaripour L, Khorramabadi RM. Glutathione ameliorates liver markers, oxidative stress and inflammatory indices in rats with renal ischemia reperfusion injury. J Renal Inj Prev. 2019; 8(2): 91 97. [DOI:10.15171/jrip.2019.18]

6. Chen WJ, Livneh H, Hsieh MH. Association of use of Chinese herbal medicines and the risk of fracture in patients with osteoporosis: a population-based cohort study. Osteoporos Int. 2019; 30(4): 807-815. [DOI:10.1007/s00198-018-4789-x]

7. Thapa A, Woo ER, Chi EY. Biflavonoids are superior to monoflavonoids in inhibiting amyloid- $\beta$ toxicity and fibrillogenesis via accumulation of nontoxic oligomer-like structures. Biochemistry. 2011; 50(13): 2445-55. [DOI:10.1021/bi101731d]

8. Merlin J. Competitive superiority by bi-flavonoids to mono-flavonoids in inhibiting amyloid- $\beta$ toxicity and fibrillogenesis through accumulating nontoxic oligomer-like structures. J Chosun Nat Sci. 2013; 6(2): 87-99. [DOI:10.13160/ricns.2013.6.2.87]

9. Lee $\mathrm{MH}$, Yoon S, Moon JO. The flavonoid naringenin inhibits dimethylnitrosamine-induced liver damage in rats. Biol Pharm Bull. 2004; 27(1): 72-6. [DOI:10.1248/bpb.27.72]

10. Andrade JK, Denadai M, de Oliveira CS, Nunes ML, Narain N. Evaluation of bioactive compounds potential and antioxidant activity of brown, green and red propolis from Brazilian northeast region. Food Res Int. 2017; 101: 129-38. [DOI:10.1016/i.foodres.2017.08.066]

11. Hernández-Aquino E, Zarco N, Casas-Grajales S. Naringenin prevents experimental liver fibrosis by blocking TGF $\beta$-Smad3 and JNK-Smad3 pathways. World J Gastroenterol. 2017; 23(24): 4354. [DOI:10.3748/wig.v23.i24.4354]

12. Lin LZ, Harnly JM. Identification of the phenolic components of chrysanthemum flower (Chrysanthemum morifolium Ramat). Food Chem. 2010; 120(1): 319-26.

[DOI:10.1016/i.foodchem.2009.09.083]

13. Gouveia S, Castilho PC. Antioxidant potential of Artemisia argentea L'Hér alcoholic extract and its relation with the phenolic composition. Food Res Int. 2011; 44(6): 1620-31.

14. Lou SN, Lai YC, Hsu YS, Ho CT. Phenolic content, antioxidant activity and effective compounds of kumquat extracted by different solvents. Food chem. 2016; 197: 1-6. [DOI:10.1016/i.foodchem.2015.10.096]
15. Peter F, Kim DH. In vitro inhibition of dihydropyridine oxidation and aflatoxin B1 activation in human liver microsomes by naringenin and other flavonoids. Carcinogenesis. 1990; 11(12): 2275-9. [DOI:10.1093/carcin/11.12.2275]

16. Hernández-Aquino E, Muriel P. Beneficial effects of naringenin in liver diseases: Molecular mechanisms. World J Gastroenterol. 2018; 24(16): 1679. [DOI:10.3748/wjg.v24.i16.1679]

17. Yen FL WT, Lin LT, Cham TM, Lin CC. Naringenin-loaded nanoparticles improve the physicochemical properties and the hepatoprotective effects of naringenin in orallyadministered rats with $\mathrm{CCl} 4$-induced acute liver failure. Pharm res. 2009; 26(4): 893-902. [DOI:10.1007/s11095-008-9791-0]

18. Sahu SC, Gray GC. Lipid peroxidation and DNA damage induced by morin and naringenin in isolated rat liver nuclei. Food Chem Toxicol. 1997; 35(5): 443-7. [DOI:10.1016/S02786915(97)00011-2]

19. Pari L, Gnanasoundari M. Influence of naringenin on oxytetracycline mediated oxidative damage in rat liver. Basic clin pharmacol toxicol. 2006; 98(5): 456-61.

[DOI:10.1111/j.17427843.2006.pto_351.x]

20. Roshankhah S, Jalili C, Salahshoor MR. Protective effects of Petroselinum crispum on ischemia/reperfusion-induced acute kidney injury in rats. Physiol Pharmacol. 2019; 23(2): 129-39.

21. Salahshoor MR, Mohammadi MM, Roshankhah SH, Najari N JC. Effect of Falcaria vulgaris on oxidative damage of liver in diabetic rats. J Diabetes Metab Disord. 2019; 7: 1-9. [DOI:10.1007/s40200019-00385-3]

22. Esfandiari E, Roshankhah S, Mardani M, et al. The effect of high frequency electric field on enhancement of chondrogenesis in human adiposederived stem cells. Iran J Basic Med Sci. 2014; 17: 571-77.

23. Wang B, Bai M, Bai Y, Li Q. Liver injury following renal ischemia reperfusion in rats. Transplant Proc. 2010; 42(9): 3422-26. [DOI:10.1016/j.transproceed.2010.09.008]

24. Seifi B, Kadkhodaee M, Delavari F, Mikaeili S, Shams S, Ostad SN. Pretreatment with pentoxifylline and $\mathrm{N}$-acetylcysteine in liver ischemia reperfusion-induced renal injury. Renal Failure. $\quad 2012 ; \quad 34(5)$ : 610-15. [DOI:10.3109/0886022X.2012.660827]

25. Basili S, Carnevale R, Nocella C. Serum albumin is inversely associated with portal vein thrombosis in cirrhosis. Hepatol Commun. 2019; 3(4): 504-12. [DOI:10.1002/hep4.1317] 
26. Jalili C, Tabatabaei H, Kakaberiei S, Roshankhah $\mathrm{SH}$, Salahshoor MR. Protective role of Crocin against nicotine-induced damages on male mice liver. Int J Prev Med. 2015; 6: 92-99. [DOI:10.4103/2008-7802.165203]

27. Chen Q, Thompson J, Hu Y, Dean J, Lesnefsky EJ. Inhibition of the ubiquitous calpains protects complex I activity and enables improved mitophagy in the heart following ischemia-reperfusion. Am J Physiol Cell Physiol. 2019; 317(5): 910-21. [DOI:10.1152/ajpcell.00190.2019]

28. Bayir Y, Karagoz Y, Karakus E. Nigella sativa reduces tissue damage in rat ovaries subjected to torsion and detorsion: oxidative stress, proinflammatory response and histopathological evaluation. Gynecol Obstet Invest. 2012; 74(1): 419. [DOI:10.1159/000336295]

29. Bayir Y, Cadirci E, Polat B. Aliskiren-a promising strategy for ovarian ischemia/reperfusion injury protection in rats via RAAS. Gynecol Endocrinol. 32(8): 675-83. [DOI:10.3109/09513590.2016.1153055]

30. Kitamura Y, Hashimoto S, Mizuta N. Fas/FasLdependent apoptosis of alveolar cells after lipopolysaccharide-induced lung injury in mice.
Am J Respir Crit Care Med. 2001; 163(3): 762-9. [DOI:10.1164/ajrccm.163.3.2003065]

31. Lee MK, Bok SH, Jeong TS. Supplementation of naringenin and its synthetic derivative alters antioxidant enzyme activities of erythrocyte and liver in high cholesterol-fed rats. Bioorg Med Chem. 2002; 10(7): 2239-44. [DOI:10.1016/S09680896(02)00059-7]

32. Wang MJ, Huang HY, Chiu TL, Chang HF, Wu HR. Peroxiredoxin 5 silencing sensitizes dopaminergic neuronal cells to rotenone via DNA damage-triggered ATM/p53/PUMA signalingmediated apoptosis. Cells. 2020; 9: 22-8. [DOI:10.3390/cells9010022]

33. Lesnefsky E, Thompson J, Hu Y, Chen Q. Knockout of p53 decreases cardiac injury by reducing ROS generation during ischemiareperfusion. FASEB J. 2017; 31(1_supplement): 624-8.

34. Ubeaud G, Hagenbach J, Vandenschrieck S, Jung L, Koffel JC. In vitro inhibition of simvastatin metabolism in rat and human liver by naringenin. Life sci. 1999; 65(13): 1403-12. [DOI:10.1016/S0024-3205(99)00380-X]

\section{How to Cite This Article:}

Roshankhah S, Abdolmaleki A, Salahshoor M R. Reduction of Renal Ischemia-Reperfusion-Induced Liver Side Effects in Rats through Antioxidative Properties of Narigenin. J Adv Med Biomed Res. 2020; 29 (132) :46-53

\section{Download citation:

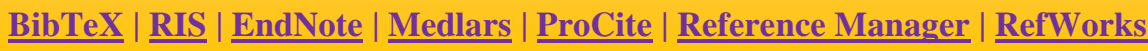

\section{Send citation to:}

Mendeley $2 \underline{\text { Zotero }}$ (-) RefWorks $\underline{\text { RefWorks }}$ 